\title{
MICROWAVE BRIGHTNESS OF POLAR FIRN AS MEASURED BY NIMBUS 5 AND 6 ESMR
}

\author{
By A. T. C. Chang, \\ (Laboratory for Atmospheric Sciences (GLAS), Goddard Space Flight Center, National \\ Aeronautics and Space Administration, Greenbelt, Maryland 2077I, U.S.A.) \\ B. J. Choudhury, \\ (Computer Sciences Corporation, Silver Spring, Maryland 209ı, U.S.A.) \\ and P. GLoersen
}

(Laboratory for Atmospheric Sciences (GLAS), Goddard Space Flight Center, National Aeronautics and Space Administration, Greenbelt, Maryland 2077I, U.S.A.)

\begin{abstract}
The microwave emission from a half-space medium characterized by coordinate dependent scattering and absorbing centers has been calculated by numerically solving the radiative transfer equation by the method of invariant imbedding. A Mie scattering phase function and surface polarization have been included in the calculation. Also included are the physical temperature profile and the temperature variation of the index of refraction for ice. Using published values of grain-size and temperature-profile data of polar firn, the brightness temperature has been calculated for the $1.55 \mathrm{~cm}$ and $0.8 \mathrm{~cm}$ wavelengths. For selected regions in Greenland and Antarctica, the results of our calculations are in reasonable agreement with the observed Nimbus-5 and Nimbus-6 ESMR data.

RÉsumé. Le rayonnement à courte longueur d'onde du névé polaire mesuré par Nimbus 5 et 6 ESMR. L'émission en micro-ondes issue d'un milieu hémispatial caractérisé par des centres coordonnés dépendants de dispersion et d'absorption a été calculée par résolution numérique de l'équation de transfert de chaleur avec la méthode de l'invariant inclus. On a pris en compte dans le calcul une fonction pour la phase de dispersion Mie et une polarisation en surface. On a également tenu compte du profil physique des températures et de la variation avec la température de l'indice de réfraction de la glace. En utilisant les valeurs publiées pour la taille des grains et les données des profils de température du névé polaire, la température de brillance a été calculée pour les longueurs d'onde de $1,55 \mathrm{~cm}$ et de $0,8 \mathrm{~cm}$. Pour des régions sélectionnées du Groenland et de l'Antarctique, les résultats de nos calculs sont en accord raisonnable avec les données observées par ESMR de Nimbus-5 et Nimbus-6.
\end{abstract}

Zusammenfassung. Helligkeit von polarem Firn im Mikrowellenbereich, gemessen von Nimbus-5 und -6 ESMR. Durch numerische Lösung der Gleichung für die Strahlungsübertragung mit der Methode der invarianten Einbettung wurde die Mikrowellen-Emission im Halbraum über einem Medium, das durch Zentren mit ortsabhängiger Streuung und Absorption charakterisiert ist, berechnet. In die Rechnung wurde eine Mie'sche Phasenfunktion der Streuung und eine Polarisation an der Oberfläche einbezogen. Desgleichen wurde das physikalische Temperaturprofil und die temperaturabhängige Schwankung des Refraktionsindex für Eis berüchsichtigt. Auf der Basis veröffentlichter Werte für die Korngrösse und das Temperaturprofil in polarem Firn wurde die Farbtemperatur für Wellenlängen von 1,55 cm und $0,8 \mathrm{~cm}$ berechnet. Für ausgewählte Gebiete in Grönland und Antarktika stehen die Rechenergebnisse in guter Übereinstimmung zu beobachteten Werten der Satelliten Nimbus-5 und Nimbus-6 ESMR.

\section{INTRODUCTION}

Brightness temperatures obtained from the electrically scanning microwave radiometers (ESMR) on board the Nimbus- 5 and Nimbus-6 spacecrafts (ESMR-5, operating at a wavelength of $1.55 \mathrm{~cm}$ and ESMR-6, at $0.8 \mathrm{~cm}$, respectively) over Greenland and Antarctica (Gloersen and others, 1974, and this paper) have shown a lack of correlation with the physical surface temperature. Model studies of microwave emission from a half-space with scattering and absorbing centers were carried out by England (1974) and by Chang and others (1976). They calculated the brightness temperature for a model snow field consisting of randomlyspaced ice spheres of different radii and dielectric properties. The scattering and extinction cross-sections were calculated using the Mie scattering theory and the brightness temperature values were then obtained by numerically solving the radiative transfer equation. Results of the calculation showed that the emerging microwave radiation originates deep within the 
medium. These results not only provided an explanation for the lack of correlation of the observed brightness temperatures and the physical surface temperatures but also opened up the possibility of remotely sensing such parameters as the snow accumulation rate and snow temperature profile.

In the model calculations performed by Chang and others (1976) and by England (1974 and 1975), the scattering and absorption properties have been assumed to be independent of the snow depth. This is in contrast to the actual situation where the crystal size does vary with the snow depth (Gow, 1969, I971). Also in the former work the physical temperature of snow has been taken to be independent of depth and in the latter calculation a linear temperature variation has been used. The accuracy of the numerical results obtained by England (1975) is difficult to assess because of the convergence problem associated with his method of solution (England, 1974). By using approximate, integrable analytic expressions for the radiative transfer equation, Zwally (1977) has obtained microwave brightness temperatures for polar ice sheet, taking into account the grain size and temperature profile variations in season and location. However, in order to obtain agreement between theory and experiment, he found it necessary to lower the calculated value of scattering coefficient by an order of magnitude. Here we have succeeded in providing an explanation for the radio brightness temperatures observed over Greenland and Antarctica with the ESMR-5 and ESMR- 6 without the need for such an adjustment to the scattering coefficient. The expression for the variation of snow grain size with depth and location used in the calculation are those compiled by Zwally (r977) by fitting the crystal size data measured by Gow (I969, I97I) at different snow depths. The radiative transfer equation (Equation (I)), has been solved numerically using these snow parameters by the method of invariant imbedding (Chandrasekhar, r950, p. I61-82; Redheffer, I962; Bellman and others, 1963, p. 5-35; Preisendorfer, I965; Grant and Hunt, I969).

\section{NUMERICAL SOLUTION FOR THE RADIATIVE TRANSFER EQUATION}

The radiative transfer equation for an axially symmetric inhomogeneous medium in which all interactions are linear can be written in the form of an integro-differential equation (Grant and Hunt, 1969)

$$
\mu \frac{\mathrm{d} I(x, \mu)}{\mathrm{d} x}=-\sigma(x) I(x, \mu)+\sigma(x)\left\{[\mathrm{I}-\omega(x)] B(x)+\frac{1}{2} \omega(x) \int_{-1}^{\mathrm{I}} p\left(x, \mu, \mu^{\prime}\right) I\left(x, \mu^{\prime}\right) \mathrm{d} \mu^{\prime}\right\},
$$

where the radiation intensity $I(x, \mu)$ is at depth $x$ traveling in the direction making an angle whose cosine is $\mu$ with the normal toward the direction of increasing $x$ (Fig. I).

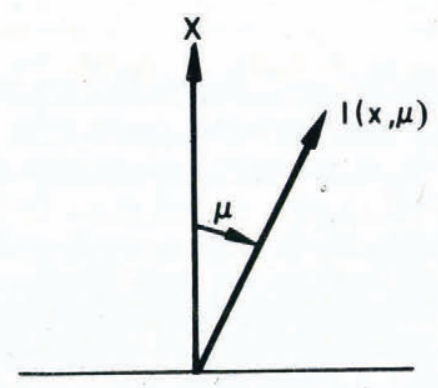

Fig. $I$. Radiation intensity of $I(x, \mu)$ is at depth $x$ traveling in a direction making an angle whose cosine is $\mu$ with the normal toward the direction of increasing $x$. 
The functions $\sigma(x), \omega(x), B(x)$, and $p\left(x, \mu, \mu^{\prime}\right)$ are prescribed functions of their arguments. They are referred to as the extinction per unit length, the single scattering albedo, the source, and the phase function, respectively. For a non-uniform medium these functions are generally piecewise continuous functions of depth subject to the conditions

$$
B(x) \geqslant 0, \quad \sigma(x) \geqslant 0, \quad 0 \leqslant \omega(x) \leqslant \mathrm{I}, \quad p\left(x, \mu, \mu^{\prime}\right) \geqslant 0 .
$$

In the present work, the following normalization for the phase function will be used

$$
\frac{1}{2} \int_{-1}^{1} p\left(x, \mu, \mu^{\prime}\right) \mathrm{d} \mu^{\prime}=\mathrm{I},
$$

for all values of $x$. Instead of working with depth $x$, one generally works with a dimensionless depth variable called optical depth $\tau$, defined in differential form as

$$
\mathrm{d} \tau=\sigma(x) \mathrm{d} x .
$$

In terms of optical depth, Equation (I) reduces to

$$
\mu \frac{\mathrm{d} I(\tau, \mu)}{\mathrm{d} \tau}=-I(\tau, \mu)+[\mathrm{I}-\omega(x)] B(x)+\frac{1}{2} \omega(\tau) \int_{-\mathbf{1}}^{1} p\left(\tau, \mu, \mu^{\prime}\right) \mathrm{d} \mu I\left(\tau, \mu^{\prime}\right) .
$$

This equation of radiative transfer was solved numerically by the invariant imbedding technique (Grant and Hunt, I969). This technique is based upon the principle that the radiation emerging from a semi-infinite plane parallel medium is invariant with respect to addition (or subtraction) of layers of arbitrary thickness to (or from) the medium. Expressed numerically, this technique solves the radiative transfer equation via matrix recurrence relations. Then by using the proper scattering phase function and the boundary conditions (England, I974, 1975), the brightness temperature emerging from the snow field can be calculated.

\section{BRIGHTNESS TEMPERATURE OF THE POLAR FIRN}

The calculation of the brightness temperature of the polar firn requires the specification of a single scattering albedo $\omega(\tau)$, physical temperature within the medium $B(\tau)$, the scattering phase matrix $p\left(\tau, \mu, \mu^{\prime}\right)$, and the reflection coefficient at the medium boundary. In the singleparticle scattering approach, the albedo can be calculated from the knowledge of the scattering and the extinction coefficients of the particle. These coefficients depend upon the radius of the particle and its refractive index. For ice particles, with which we are concerned, the specification of size is sufficient to determine the scattering coefficient. The extinction coefficient of the particle on the other hand depends on the imaginary part of the index of refraction which is less sensitive to the crystal size. Calculations of Chang and others (1976) show that for ice at $273 \mathrm{~K}$ the extinction coefficient is about an order of magnitude higher than for ice at $253 \mathrm{~K}$. Although this sensitivity can be used to distinguish temperature profiles, it also introduces some uncertainty in quantitative comparison with remotely-measured brightness temperature. It is also to be noted that the imaginary part of the index of refraction changes considerably with the presence of impurities (Hoekstra and Cappillino, I97I). For continental ice sheets the effect of impurities may be negligible.

Zwally (1977) has performed a regression study of the crystal-size data for different snow depths obtained by Gow (1969, I971) at various locations in Greenland and Antarctica. In Table I we show the crystal-size profiles, for which we have calculated the brightness temperature. 
TABle I. Location AND MEAN ANNUAL SURface TEMPERATURE AND MEAN CRYSTAL-SIZE PROFILE (ZWALLY, 1977)

\begin{tabular}{|c|c|c|}
\hline Location & $\underset{\mathrm{K}}{T_{\mathrm{m}} *}$ & $\stackrel{r}{\mathrm{~mm}}$ \\
\hline $\begin{array}{l}\text { Byrd Station, Antarctica } \\
\text { lat. } 79^{\circ} 59^{\prime} \text { S., long. } 120^{\circ} \text { oI }^{\prime} \mathrm{W} .\end{array}$ & 245 & $(0.026+0.00166 z)^{\frac{1}{3}}$ \\
\hline $\begin{array}{l}\text { Camp Century, Greenland } \\
\text { lat. } 77^{\circ} \mathrm{II}^{\prime} \mathrm{N} \text {., long. } 6 \mathrm{I}^{\circ}{ }^{\prime} \mathrm{I}^{\prime} \mathrm{W} \text {. }\end{array}$ & 249 & $(0.028+0.0111 z)^{1}$ \\
\hline $\begin{array}{l}\text { Inge Lehmann, Greenland } \\
\text { lat. } 77^{\circ} 57^{\prime} \text { N., long. } 39^{\circ} 1^{\prime} \mathrm{W} .\end{array}$ & 243 & $(0.028+0.0202 z)^{t}$ \\
\hline
\end{tabular}

* Mean annual surface temperature. $z$ is snow depth in meters.

We have mentioned that absorption per unit length is quite insensitive to the crystal size and depends largely on the imaginary part of the refractive index $n^{\prime \prime}$. Although the choice of $n^{\prime \prime}$ is not completely arbitrary, its exact value is difficult to obtain. In this study we have developed an interpolation/extrapolation algorithm to determine the index of refraction of ice from experimental data (Evans, I965, fig. 7). Table II shows the experimental data for $n^{\prime \prime}$ and the interpolated and extrapolated values for $1.55 \mathrm{~cm}$ and $0.8 \mathrm{~cm}$ wavelengths. The interpolated values for $3.2 \mathrm{~cm}$ differ from the measured values reported by Cumming (1952). These differences are probably caused by the structure of the different ice types tested.

TABle II. The IMAginary PART INDEX OF REFRACTION FOR ICE AT DIFFERENT WAVELENGTHS AND TEMPERATURES

\begin{tabular}{|c|c|c|c|c|c|c|}
\hline \multirow[b]{2}{*}{$\begin{array}{c}\text { Temperature } \\
\mathrm{K}\end{array}$} & \multicolumn{4}{|c|}{ Experimental } & \multirow{2}{*}{ 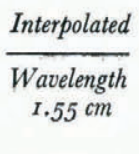 } & \multirow{2}{*}{$\begin{array}{c}\text { Extrapolated } \\
\text { Wavelength } \\
0.8 \mathrm{~cm}\end{array}$} \\
\hline & $\begin{array}{c}\text { Wavelength } \\
30 \mathrm{~cm}\end{array}$ & $\begin{array}{c}\text { Wavelength } \\
\quad 10 \mathrm{~cm}\end{array}$ & $\begin{array}{l}\text { Wavelength } \\
3 \mathrm{~cm}\end{array}$ & $\begin{array}{l}\text { Wavelength } \\
\quad 1 \mathrm{~cm}\end{array}$ & & \\
\hline 273 & 0.00037 & 0.00042 & $0.0005^{2}$ & 0.00023 & $0.0003^{8}$ & 0.00013 \\
\hline 253 & 0.00015 & 0.00023 & 0.00029 & 0.00019 & 0.00024 & 0.00015 \\
\hline 233 & 0.000 I0 & 0.00017 & 0.000 1 8 & 0.00014 & 0.00016 & 0.00013 \\
\hline 213 & 0,00004 & $0.000 \mathrm{I} 2$ & 0.000 og & 0.00012 & 0.00010 & 0.000 I 3 \\
\hline
\end{tabular}

The single-scattering albedo is defined as

$$
\omega=\frac{\gamma_{\mathrm{s}}}{\gamma_{\mathrm{a}}+\gamma_{\mathrm{s}}} .
$$

Therefore, the depth variation of $\omega$ depends on the depth variation of $\gamma_{\mathrm{s}}$ and $\gamma_{\mathrm{a}}$. Since $\gamma_{\mathrm{a}}$ varies with the physical temperature (Cumming, 1952) of the snow, an analytic expression for depth and seasonal variation of polar snow temperature has been used (Zwally, 1977).

$$
B(z, t)=250-\mathrm{I} 5 \exp (-0.3 z) \cos [0.99(t-84)-(97+20 z)] \text {. }
$$

The maximum surface temperature occurs at time $t=0$ and $t=365 \mathrm{~d}$ and minimum temperature is for time $t=(365 / 2) \mathrm{d}$. The mean temperature of the surface and the asymptotic temperature is $250 \mathrm{~K}$ and the peak-to-peak variation at the surface is $30 \mathrm{~K}$. This mean temperature is quite acceptable for the locations given in Table I.

The correct value of $n^{\prime \prime}$ is crucial because the absorption coefficient $\gamma_{\mathrm{a}}$ depends on this value. To illustrate the effect of different values of $n^{\prime \prime}$, a single calculation has been performed. The Camp Century, Greenland, site was chosen for the comparison. Figure 2 shows the variation of vertically-polarized brightness temperature by fixing the $n^{\prime \prime}$ in each calculation, while the other parameters were remained the same as in the other calculations. 


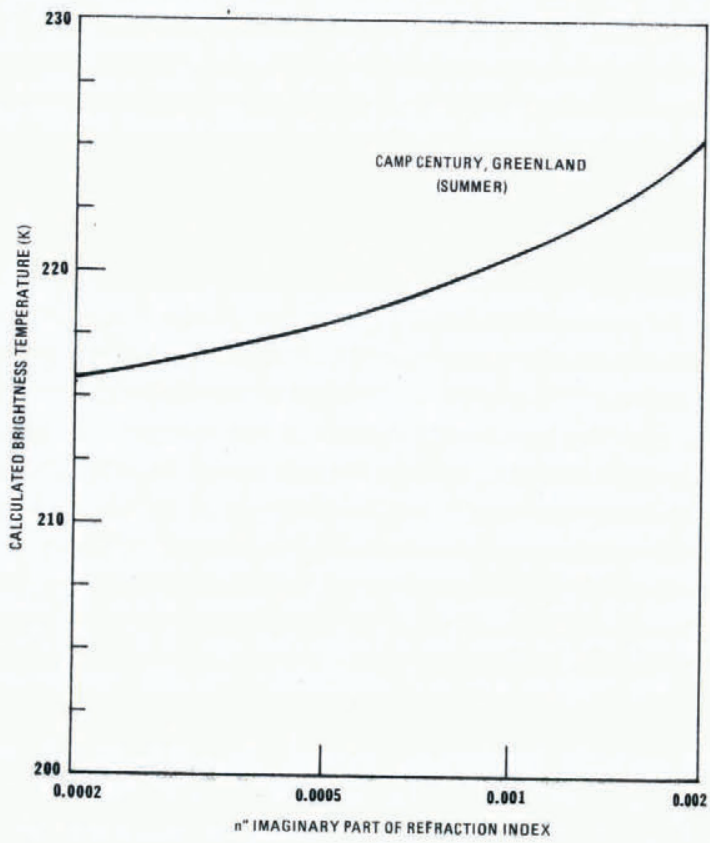

Fig. 2. Dependence of $0.8 \mathrm{~cm}$ vertically polarized brightness temperature on $n^{\prime \prime}$ the imaginary part of index of refraction.

Calculated brightness-temperature values for several locations and times are given in Table III. The agreement between the calculated and the observed ESMR-5 values are considered quite good. The r.m.s. deviation between the calculated brightness temperature and the observed brightness temperature for ESMR- 5 is $8.4 \mathrm{~K}$. The agreement between the calculated brightness temperature and the observed ESMR-6 values is not as good as the ESMR-5, with r.m.s. deviation of $14.5 \mathrm{~K}$ and $20.4 \mathrm{~K}$ for ESMR-6 vertical and horizontal polarization respectively. The differences in r.m.s. deviation for the calculated ESMR-5 and ESMR-6 values are attributable at least in part to the following factors: ( 1 ) the observed seasonal variations in the brightness temperature larger than those calculated indicate that the microwave emission for $0.8 \mathrm{~cm}$ wavelength largely emanates from a thin surface layer and

TABle III. Comparison of ObSERved and Calculated Brightness temperatures of locations in TABle I

\begin{tabular}{|c|c|c|c|c|c|c|c|}
\hline \multirow[b]{2}{*}{ Location } & \multirow[b]{2}{*}{$\begin{array}{l}t^{*} \\
\mathrm{~d}\end{array}$} & \multicolumn{2}{|c|}{ Nimbus-5 ESMR } & \multicolumn{2}{|c|}{$\begin{array}{c}\text { Nimbus-6 ESMR } \\
\text { (vertical polarization) }\end{array}$} & \multicolumn{2}{|c|}{$\begin{array}{c}\text { Nimbus-6 ESMR } \\
\text { (horizontal polarization) }\end{array}$} \\
\hline & & $\begin{array}{l}\text { Calculated } \\
\mathrm{K}\end{array}$ & $\begin{array}{l}\text { Observed } \\
\mathrm{K}\end{array}$ & $\begin{array}{l}\text { Calculated } \\
\mathrm{K}\end{array}$ & $\begin{array}{l}\text { Observed } \\
\mathrm{K}\end{array}$ & $\begin{array}{l}\text { Calculated } \\
\mathrm{K}\end{array}$ & $\begin{array}{c}\text { Observed } \\
\mathrm{K}\end{array}$ \\
\hline \multirow[t]{3}{*}{ Byrd Station, Antarctica } & & 220 & 210 & 210 & 226 & 174 & I 76 \\
\hline & $365 / 4$ & 215 & 205 & 204 & 196 & 170 & 144 \\
\hline & $365 / 2$ & 202 & 200 & $19^{2}$ & 197 & 160 & 146 \\
\hline \multirow[t]{3}{*}{ Camp Century, Greenland } & o & 232 & 225 & 214 & 236 & 175 & 209 \\
\hline & $365 / 4$ & 224 & 215 & 207 & 213 & 173 & 179 \\
\hline & $365 / 2$ & 212 & 210 & 195 & 206 & 163 & 168 \\
\hline \multirow[t]{3}{*}{ Inge Lehmann, Greenland } & 0 & 215 & 225 & 210 & 203 & I 75 & 160 \\
\hline & $365 / 4$ & 209 & 209 & 204 & 180 & 170 & 150 \\
\hline & $365 / 2$ & 196 & 210 & 192 & I 75 & 162 & 130 \\
\hline
\end{tabular}

* $t$ is the time parameter as shown in Equation (7). 
thus the values assumed for $n^{\prime \prime}$ at this wavelength were too low. As a result, the calculated extinction coefficient is too small, resulting in too large a penetration depth, (2) sensitivity to near-surface moisture due to solar heating of snow. in the presence of below-freezing air temperature, and (3) the inherent difficulties in the calibration of ESMR-6 due to the spacecraft thermal conditions.

\section{SumMARY AND GONGLUSIONS}

A microscopic single-particle scattering model has been used along with the measured variation of crystal size and temperature with depth to provide a quantitative explanation of observed brightness temperatures of the South Polar and North Polar regions. This extends the calculations performed by Chang and others (1976) by taking into account the variations of grain size and temperature with depth. The calculated brightness temperatures for $\mathrm{I} .55 \mathrm{~cm}$ wavelength are in good agreement with the observations, but one of the calculated brightness temperatures for $0.8 \mathrm{~cm}$ wavelength differs by $32 \mathrm{~K}$ with the observations. The probable causes of these discrepancies are: (I) uncertainty in the calibration of the ESMR-6 instrument, and (2) uncertainty in the values of $n^{\prime \prime}$. In some areas of Greenland, percolation is known to occur, which is accompanied by a large change in $n^{\prime \prime}$. Since we felt that sufficiently accurate values of $n^{\prime \prime}$ in this region are not available, we did not consider these areas in our comparisons.

Based on the single-particle scattering model, the calculated brightness temperatures correspond to the data obtained from the ESMR 5 and ESMR 6 over selected sites in Greenland and Antarctica. Using essentially the same temperature and grain-size profile that were used by Zwally (1977), we find that our calculated brightness temperatures for $1.55 \mathrm{~cm}$ wavelength are significantly higher than his. This discrepancy is probably due to the approximate analytic solution of the radiative transfer equation used in his calculations of the brightness-temperature values. In view of these findings, our calculations would provide a more realistic brightness-temperature estimate for the polar firn.

Apart from the independent-particle scattering model discussed above, there are alternate explanations for the source of microwave scattering and absorption for radio brightness temperatures of Antarctica and continental glaciers which have been studied by Gurvich and others (1973), Stogryn (1974), and Tsang and Kong (1976). In these studies, the source of microwave scattering is the fluctuation of the dielectric constant of the media (Tatarskiy, 1959, English translation, p. 59-70). A special case of such fluctuations occurring where freeze-thaw cycles have taken place, accompanied by percolation of melt water and formation of sub-surface ice lenses, has been identified as important particularly at the longer wavelengths where single-particle scattering is of lesser importance (private communication from P. Gudmundsen in 1978). The calculated brightness temperature based on these models, depends upon the variance and the correlation length of the fluctuation of the dielectric media. Physically this scattering mechanism is as plausible as scattering by independent ice grains, and it is reasonable to believe that these two scattering mechanisms co-exist in the medium and should be considered together in the quantitative calculation.

MS. received 22 November 1978 and in revised form Io April 1979

\section{REFERENCES}

Bellman, R. E., and others. I963. Invariant imbedding and radiative transfer in slabs of finite thickness, by R. E. Bellman, R. E. Kalaba, and M. C. Prestrud. New York, American Elsevier Publishing.

Chandrasekhar, S. I950. Radiative transfer. Oxford, Clarendon Press.

Chang, T. C., and others. 1976. Microwave emission from snow and glacier ice, by T. C. Chang, P. Gloersen, T. Schmugge, T. T. Wilheit, and H. J. Zwally. Fournal of Glaciology, Vol. I6, No. 74, p. 23-39. 
Cumming, W. A. 1952. The dielectric properties of ice and snow at 3.2 centimeters. Fournal of Applied Physics, Vol. 23, No. 7, p. 768-73.

England, A. W. 1974. Thermal microwave emission from a half-space containing scatterers. Radio Science, Vol. 9, No. 4, p. 447-54.

England, A. W. 1975. Thermal microwave emission from scattering layer. journal of Geophysical Research, Vol. 8o, No. 32, p. 4484-96.

Evans, S. 1965 . Dielectric properties of ice and snow-a review. Fournal of Glaciology, Vol. 5, No. 42, p. 773-92.

Gloersen, P., and others. 1974. Microwave maps of the polar ice of the Earth, [by] P. Gloersen, T. T. Wilheit, T. C. Chang and W. Nordberg, and W. J. Campbell. Bulletin of the American Meteorological Society, Vol. 55, No. 12, p. $1442-48$.

Gow, A. J. I 969 . On the rate of growth of grains and crystals in South Polar firn. Fournal of Glaciology, Vol. 8, No. 53 , p. $241-52$.

Gow, A. J. r971. Depth-time-temperature relationships of ice crystal growth in polar regions. U.S. Cold Regions Research and Engineering Laboratory. Research Report 300.

Grant, I. P., and Hunt, G. E. 1969 . Discrete space theory of radiative transfer. Proceedings of the Royal Society of London, Ser. A, Vol. 313, No. 1513, p. 199-216.

Gurvich, A. S., and others. I 973 . Vliyaniye vnutrenney struktury lednikov na ikh teplovoye radioizlucheniye [The influence of the internal structure of glaciers on their thermal radio radiation]. [By] A. S. Gurvich, V. I. Kalinin, D. T. Matveyev. Fizika Atmosfery $i$ Okeana, Tom 9, No. 12, p. 1247-56. [English translation: Physics of the Atmosphere and Ocean, Vol. 9, No. 12, 1973, p. 712-17.]

Hoekstra, P., and Cappillino, P. I 97 I. Dielectric properties of sea and sodium chloride ice at UHF and microwave frequencies. Journal of Geophysical Research, Vol. 76, No. 20, p. 4922-31.

Preisendorfer, R. W. 1965. Radiative transfer in discrete spaces. Oxford, Pergamon Press.

Redheffer, R. 1962 . On the relation of transmission-line theory to scattering and transfer. Fournal of Mathematics and Physics, Vol. 41, No. I, p. I-41.

Stogryn, A. 1974. Electromagnetic scattering by random dielectric constant fluctuations in a bounded medium. Radio Science, Vol. 9, No. 5, p. 509-18.

Tatarskiy, V. I. 1959. Teoriya fluktuatsionnykh yavlenii pri rasprostranenii voln v turbulentnoy atmosfere. Moscow, Izdatel'stvo Akademii Nauk SSSR. [English translation: Wave propagation in a turbulent medium, translated from Russian by R. A. Silverman. New York, McGraw-Hill Book Co., Inc., 1961.]

Tsang, L., and Kong, J. A. 1976. Thermal microwave emission from half-space random medium. Radio Science, Vol. I I, No. 7, p. 599-6o9.

Zwally, H. J. 1977. Microwave emissivity and accumulation rate of polar firn. Fournal of Glaciology, Vol. 18, No. 79, p. $195^{-215}$. 